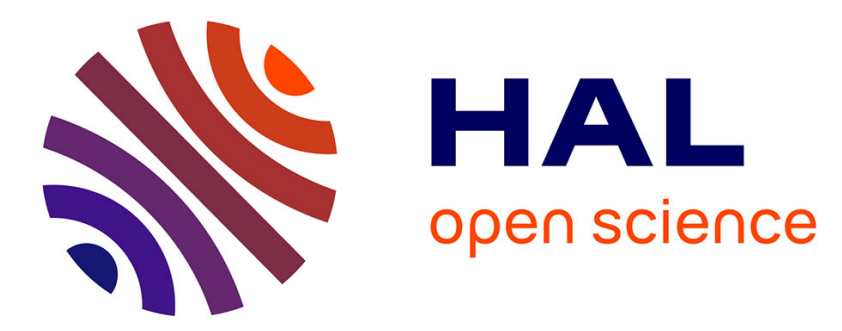

\title{
The Development of a Miniature Optical Sensor for Balloon-Borne Measurements of Ozone Profiles
}

Mareile A. Wolff, Andreas Herber, Hans-Werner Jacobi, Otto Schrems, Jan Hoops, Wilfried Ruhe

\section{- To cite this version:}

Mareile A. Wolff, Andreas Herber, Hans-Werner Jacobi, Otto Schrems, Jan Hoops, et al.. The Development of a Miniature Optical Sensor for Balloon-Borne Measurements of Ozone Profiles. Journal of Atmospheric and Oceanic Technology, 2008, 25 (1), pp.57 à 70. 10.1175/2007JTECHA844.1 . insu-00381153

\section{HAL Id: insu-00381153 \\ https://hal-insu.archives-ouvertes.fr/insu-00381153}

Submitted on 3 Mar 2021

HAL is a multi-disciplinary open access archive for the deposit and dissemination of scientific research documents, whether they are published or not. The documents may come from teaching and research institutions in France or abroad, or from public or private research centers.
L'archive ouverte pluridisciplinaire HAL, est destinée au dépôt et à la diffusion de documents scientifiques de niveau recherche, publiés ou non, émanant des établissements d'enseignement et de recherche français ou étrangers, des laboratoires publics ou privés. 


\title{
The Development of a Miniature Optical Sensor for Balloon-Borne Measurements of Ozone Profiles
}

\author{
Mareile A. Wolff, ${ }^{*}$ Andreas Herber, Hans-Werner Jacobi, and Otto Schrems \\ Alfred Wegener Institute for Polar and Marine Research, Bremerhaven, Germany \\ JAN HOOPS \\ iSiTEC GmbH, Bremerhaven, Germany
}

WILFRIED RUHE

impres GmbH, Bremen, Germany

(Manuscript received 15 March 2006, in final form 1 March 2007)

\begin{abstract}
A new autonomous balloon-borne sounding system for the measurement of stratospheric trace gas profiles was designed and constructed. Major components of the sonde are a miniature grating spectrometer, which covers a wavelength range from the ultraviolet $(200 \mathrm{~nm})$ to the visible $(850 \mathrm{~nm})$, and a commercial radiosonde. The low-weight sonde (approximately $1.7 \mathrm{~kg}$ ) measures the spectral solar irradiance and meteorological parameters during the ascent through the atmosphere. Because of the decreasing ambient temperature during an ascent, the temperature of the spectrometer decreases by about $15 \mathrm{~K}$. Active temperature stabilization is not included, and the irradiance measurements show a strong temperature dependence. The temperature-induced wavelength shift, the absolute irradiance, and the dark signal behavior were characterized as a function of the spectrometer's temperature. Based on this laboratory characterization, an inflight correction for changes in the dark current and for the wavelength drift was applied. In the test program described herein, ozone profiles were determined from changes in the measured solar spectral irradiance caused by ozone absorption in the Hartley and Huggins bands. Comparisons were performed with results of simultaneous electrochemical ozonesonde and lidar measurements. The ozone number density profile retrieved using the new sonde agrees with the independently measured ozone profiles within $20 \%$ for altitudes above $18 \mathrm{~km}$. In the lower stratosphere, the discrepancies increase to $50 \%$.
\end{abstract}

\section{Introduction}

The concentration of a variety of trace gases in the troposphere and stratosphere plays a major role in issues like air quality, global climate change, and the destruction of the ozone layer. For example, WMO (2003) and Singh and Fabian (2003) emphasize the need of precise ozone measurements with a high vertical resolution throughout the entire stratosphere in order to

\footnotetext{
* Current affiliation: Department of Physics, University of Toronto, Toronto, ON, Canada.
}

Corresponding author address: Mareile A. Wolff, Dept. of Physics, University of Toronto, 60 St. George St., Toronto, ON M5S 1A7, Canada.

E-mail: mwolff@atmosp.physics.utoronto.ca detect the early signs of a possible recovery of the ozone layer. The concentration of atmospheric ozone, as well as of other trace gases, can be determined by optical absorption measurements. Optical instruments are used on board satellites for monitoring the chemical composition of the atmosphere. For the necessary validation of spaceborne data, highly accurate and simultaneous measurements of various trace gases are performed by optical sensors carried by large-size balloons (e.g., Strong et al. 2005; Wursteisen 2003). Because of the elaborate logistic requirements, these experiments are very expensive and can only be started from a small number of launching sites, and thus are very limited in number.

Ozone trends in the upper-troposphere/lowerstratosphere region are based on worldwide routine measurements with electrochemical [Brewer-Mast (BM) or electrochemical concentration cell (ECC)] bal- 
loon-borne sondes (e.g., Solomon et al. 2005; Logan et al. 1999). With this simple and inexpensive method, reliable ozone values can be measured to an altitude of up to approximately $30 \mathrm{~km}$ (SPARC 1998). The precision of the different sonde types varies between $5 \%$ and $15 \%$ in the troposphere and between $3 \%$ and $8 \%$ in the altitude range between the tropopause and $28 \mathrm{~km}$.

Above $28 \mathrm{~km}$, the quality of the electrochemical sondes is strongly influenced by the performance of the air sampling pump and its decaying efficiency at lower pressures. The BM sonde systematically underestimates the ozone concentrations, resulting in deviations of $-15 \%$ at $30 \mathrm{~km}$ (SPARC 1998). The accuracy of the ECC is about $5 \%$ at an altitude of $30 \mathrm{~km}$ and decreases to $-14 \%$ to $+6 \%$ at $38 \mathrm{~km}$ (Komhyr et al. 1995).

In recent years, small-size and low-cost spectrometers have been launched onto the market. A balloonborne sonde based on such a miniature spectrometer offers the benefits of optical methods (simultaneously measuring various trace gases and providing more reliable measurements at higher altitudes) at moderate costs, requiring logistic efforts comparable to the electrochemical sondes. Our goal was to develop and realize a prototype sonde, characterized by small size, and low weight and power consumption, allowing launches independent from specially equipped launching sites or additional instrumentation, and to prove that trace gas retrievals are possible with such a low-cost/low-effort optical sonde.

In this paper the technical details of the newly developed sounding system are presented. Experimental details are given about the laboratory measurements performed to characterize the optical properties of the spectrometer as a function of temperature. We show the spectral irradiance measured during a balloonborne flight of the instrument and describe a simple algorithm for the determination of the vertical ozone distribution. The resulting ozone profile is compared to independent measurements.

\section{Operating principle}

Optical measurements of trace gas abundances are based on the optical properties of molecules in the gas phase and their interaction with electromagnetic radiation passing through the atmosphere. Each species is characterized by specific absorption and emission lines or bands.

As a first application, ozone profiles were derived from the observed irradiance spectra with the new sonde. By measuring the incoming solar radiation at different altitudes (step A in Fig. 1), the attenuation of light passing through defined layers of the atmosphere

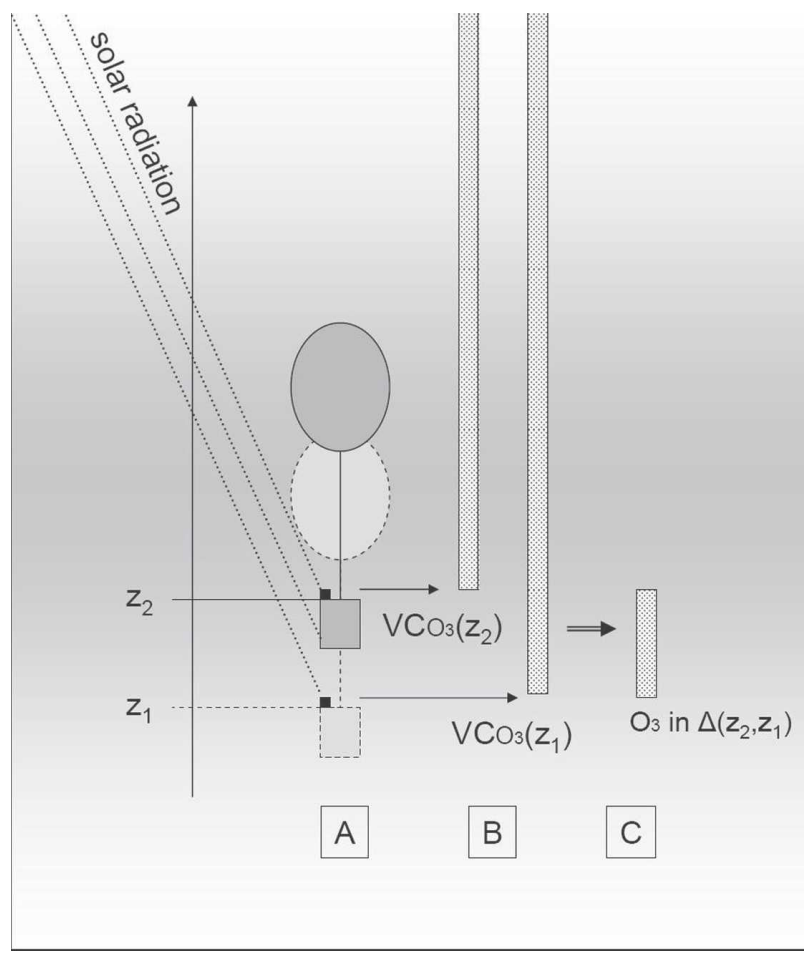

FIG. 1. Schematic illustration of the detection principle. Step A: measurement of solar radiation in different altitudes $\left(z_{1}\right.$ and $\left.z_{2}\right)$. Step B: determination of total ozone columns $\mathrm{VC}_{\mathrm{O}_{3}}(z)$ above the different measurement altitudes. Step C: calculation of ozone concentration in an altitude layer by differentiation of total ozone column amounts.

can be calculated. The attenuation provides information on the number of molecules of the absorbing trace gas (here: ozone) in a given layer. According to the algorithm developed for the Dobson spectrophotometer (e.g., Dobson 1957; Komhyr 1980), the ozone amount in the vertical column of air extending from the altitude $z$ of the sonde to the top of the atmosphere was determined during the ascent of the sonde (step B in Fig. 1).

The algorithm used in this work is based on measuring the relative intensities of the direct radiation of selected pairs of ultraviolet wavelengths, called the A, B, $\mathrm{C}$, and $\mathrm{D}$ wavelength pairs (Table 1 ). The shorter wavelength of each pair is located within an absorption band of ozone, whereas the longer wavelength is relatively unaffected by ozone. On the way through the atmosphere to the instrument the radiation at both wavelengths is attenuated because of scattering by air molecules and aerosols. If ozone molecules are present, the intensity of the shorter wavelength decreases more than the intensity of the longer wavelength. Therefore, the relative intensity measured in the altitude $z$ varies with the amount of ozone present in the atmosphere above altitude $z$. 
TABLE 1. The Dobson wavelengths and their effective ozone absorption cross sections and Rayleigh optical depths. Both are convoluted with the instrument's slit function.

\begin{tabular}{lccccc}
\hline \hline & $\lambda$ & & & & \\
No. & $(\mathrm{nm})$ & $\sigma_{\mathrm{O}_{3}}\left(\mathrm{~cm}^{2}\right)$ & $\Delta \sigma_{\mathrm{O}_{3}}$ & $\tau_{\text {Ray }}$ & $\Delta \tau_{\text {Ray }}$ \\
\hline$A_{1}$ & 305.5 & $1.6658 \times 10^{-19}$ & & 1.1265 & \\
$A_{2}$ & 325.4 & $1.1555 \times 10^{-20}$ & & 0.8600 & \\
$\Delta_{A}$ & & & $1.55025 \times 10^{-19}$ & & 0.2665 \\
$B_{1}$ & 308.8 & $1.0926 \times 10^{-19}$ & & 1.0757 & \\
$B_{2}$ & 329.1 & $4.4614 \times 10^{-21}$ & & 0.8197 & \\
$\Delta_{B}$ & & & $1.047986 \times 10^{-19}$ & & 0.2560 \\
$C_{1}$ & 314.5 & $4.7069 \times 10^{-20}$ & & 0.9946 & \\
$C_{2}$ & 332.4 & $2.5021 \times 10^{-21}$ & & 0.7857 & \\
$\Delta_{C}$ & & & $4.45669 \times 10^{-20}$ & & 0.2089 \\
$D_{1}$ & 317.6 & $3.2650 \times 10^{-20}$ & & 0.9537 & \\
$D_{2}$ & 339.8 & $1.0751 \times 10^{-21}$ & & 0.7159 & \\
$\Delta_{D}$ & & & $3.54249 \times 10^{-20}$ & & 0.2378 \\
\hline
\end{tabular}

Although the attenuation caused by the Mie scattering from aerosols varies little over the wavelength range from 305 to $340 \mathrm{~nm}$, the differences between the Mie scattering coefficients at the two wavelengths of one pair are not zero. Therefore, Komhyr (1980) recommends the calculation of ozone data from observations on double-pair wavelengths. The nearly equal wavelength differences of both wavelength pairs allow the assumption that the difference of the differences between the Mie scattering coefficients at the two wavelengths of each pair is zero.

The ozone concentration profile is derived by differentiating the ozone vertical columns (step C in Fig. 1).

\section{Instrumental design}

The new instrument includes sensors to measure the spectral solar irradiance and meteorological data simultaneously. A full description of the technical details of this Platform Independent Optical Sensor (PIOS) can be found elsewhere (Wolff 2005). Here we describe the balloon-borne version of PIOS (Wolff and Ruhe 2004). The sonde consists of three main modules: (i) a miniature grating spectrometer (USB2000UV/vis, Ocean Optics, Inc., Florida); (ii) a controlling unit (iSiTec $\mathrm{GmbH}$, Germany), which synchronizes the optical and the meteorological datasets and prepares them for transmitting; and (iii) a radiosonde (SRS-C34, Meteolabor AG, Switzerland), which measures pressure, temperature, humidity, and GPS position, and, furthermore, transmits the dataset to a ground station.

Figure 2 shows the schematic instrument design. Separate power supplies have been established using lithium batteries: $10.5 \mathrm{~V}$ for (i) the spectrometer and (ii) the controlling unit, and $9 \mathrm{~V}$ for (iii) the radiosonde to avoid electromagnetic interference between the

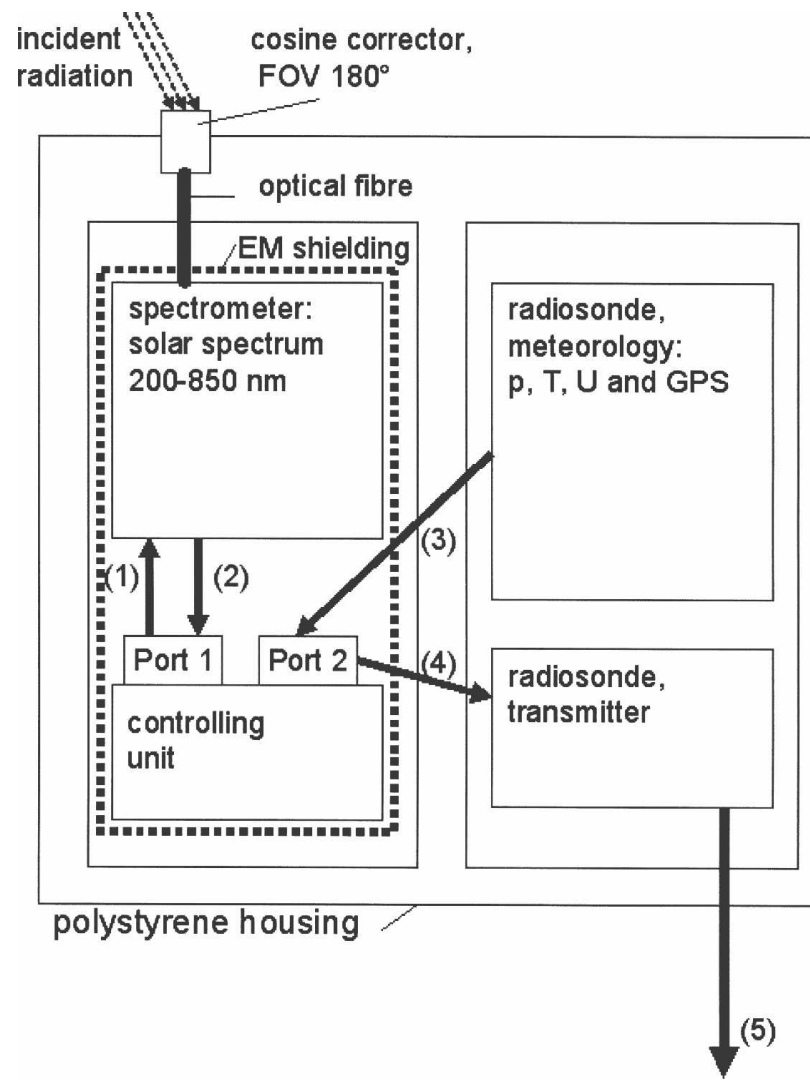

FIG. 2. Schematic setup of the optical sensor. The numbered arrows represent the data flow: 1) control of integration time, 2) transfer of optical data, 3) transfer of meteorological data, 4) transfer of synchronized dataset (optical and meteorological data), and 5) radio transfer of combined dataset to the ground station. For laboratory experiments a computer can be connected directly to port 1 and port 2 for data output and controlling.

components. For the same reason, the controlling unit and the spectrometer are shielded by an aluminum box. The polystyrene casing of the complete system has the package dimensions of $345 \times 210 \times 180 \mathrm{~mm}^{3}$. The weight of the overall payload amounts to $1.7 \mathrm{~kg}$.

\section{a. Spectrometer and sampling}

The upward-looking optical entrance is mounted on top of the sonde. Shadowing effects by the balloon are minimized by the $100-\mathrm{m}$ distance between balloon and sonde, using an extra long unwinder. The incident radiation enters the system via a cosine corrector (CC-3UV, Ocean Optics, Inc.) with a field of view (FOV) of $180^{\circ}$, which allows measurements with the sun visible most of the time under different sun elevations despite movements of the payload. Furthermore, the cosine corrector reduces the oscillation effect of the incoming radiation caused by the swinging of the payload. The 
diffusing material consists of a thin plane disk of polytetrafluoroethylene that is located at the end of a stainless steel barrel with a diameter of $6.3 \mathrm{~mm}$. The angular response of the type of cosine corrector used can be found online at the manufacturer's Web site (Ocean Optics 2006). It shows a deviation from the ideal cosine response of less than $5 \%$ for incident angles less than $45^{\circ}$ and about $10 \%$ for incident angles between $45^{\circ}$ and $60^{\circ}$. Above $60^{\circ}$ the deviation increases further. A fiber optic (length $40 \mathrm{~cm}$, diameter $400 \mu \mathrm{m}$ ) directs the light from the diffuser into the spectrometer. A grating with 600 lines per millimeter blazed at $300 \mathrm{~nm}$ was selected to cover a wavelength range between 200 and $850 \mathrm{~nm}$. The dispersed light is detected with a built-in 2048channel charge-coupled device (CCD) array (Sony ILX511). The entrance slit of the spectrometer has a width of $25 \mu \mathrm{m}$, and its optical resolution is $1.34 \mathrm{~nm}$ full width at half maximum (FWHM; Ocean Optics 2005). For this study the spectrometer operated with integration times between 20 and $1000 \mathrm{~ms}$. Table 2 summarizes the specifications of the spectrometer and its optical characteristics as provided by the manufacturer.

\section{b. Radiosonde: Meteorology and radio transmitter}

The meteorological conditions, that is, air temperature, air pressure, relative humidity, and GPS position, were measured with the radiosonde. A detailed description of the instrumentation is given by Richner and von Hünerbein (1999). In addition, a second temperature sensor was glued to the spectrometer to measure the spectrometer's temperature. Table 3 lists the main characteristics of the sensors. The altitude of the sonde is determined by two independent methods: (i) pressure measurement and (ii) GPS altitude. The hypsometer compensates for short GPS outages that mainly occur in lower altitudes. The hypsometer delivers reliable data until about $35 \mathrm{~km}$. At that altitude the pressure reaches the triple point of water $(6.1 \mathrm{hPa})$. Above

TABLE 2. Optical specifications of the miniature spectrometer USB2000 UV/VIS (Ocean Optics, Inc.) used in the PIOS sensor (Ocean Optics 2003).

\begin{tabular}{ll}
\hline \hline \multicolumn{1}{c}{ Dimensions } & \multicolumn{1}{c}{$90 \times 65 \times 35 \mathrm{~mm}^{3}$} \\
\hline Weight & $190 \mathrm{~g}$ \\
Entrance slit & $25 \mu \mathrm{m}$ \\
Grating & 600 lines per mm blazed at $300 \mathrm{~nm}$ \\
Detector & CCD array 2048 channels, Sony ILX511 \\
Integration time & $3-30000 \mathrm{~ms}$ \\
Stray light & $\leq 0.05 \%$ at $600 \mathrm{~nm}, \leq 0.1 \%$ at $435 \mathrm{~nm}$ \\
Resolution & $1.34 \mathrm{~nm} \mathrm{FWHM}$ \\
Operating conditions & $-10^{\circ}$ to $+60^{\circ} \mathrm{C}$ \\
Interface & $\mathrm{USB} 1.1,12 \mathrm{Mbps}$ 2-wire RS-232 \\
\hline
\end{tabular}

TABLE 3. Sensors and their characteristics of the radiosounding system SRS-CR34 (Meteolabor AG). A detailed description of the used sensors can be found in Richner and von Hünerbein (1999).

\begin{tabular}{|c|c|c|c|}
\hline Parameter & Sensor & Range & Error \\
\hline Temperature & $\begin{array}{l}\text { Copper-constantan } \\
\text { thermocouple }\end{array}$ & $-100^{\circ}$ to $+60^{\circ} \mathrm{C}$ & $\pm 0.1 \mathrm{~K}$ \\
\hline Pressure & $\begin{array}{l}\text { Hypsometer with } \\
\text { distilled water }\end{array}$ & $\begin{array}{l}-10^{\circ} \text { to }+110^{\circ} \mathrm{C} \\
6-1000 \mathrm{hPa}\end{array}$ & $\begin{array}{l} \pm 0.1 \mathrm{~K} \\
\leq 1 \%\end{array}$ \\
\hline Humidity & Carbon element & $\begin{array}{l}-60^{\circ} \text { to }+40^{\circ} \mathrm{C} \\
0 \%-100 \%\end{array}$ & $2 \%$ \\
\hline
\end{tabular}

this level the altitude can only be determined using the GPS data.

The transmitter of the radiosonde sends the synchronized dataset (optical and meteorological data) to a ground station at a rate of 2400 baud. The signal can be received with a UHF antenna and receiver, such as the AR8600 (AOR, Ltd., Japan) or Digicora (Vaisala, Inc., Finland). The receiver is connected to a computer via an interface unit (ARGUS 37, Meteolabor AG) belonging to the commercial radiosonde system. Data decoding and recording are achieved with software developed for this purpose. All raw data are displayed in real time at the ground station and stored for further processing.

\section{c. Controlling unit}

The microprocessor-based controlling unit offers two ports for the incoming optical (port 1) and meteorological (port 2) data. The controlling unit evaluates, synchronizes, and prepares the optical and the meteorological datasets for transmission. The fixed baud rate of the radiosonde limits the transmission of optical data to 1000 preselected channels for a 10 -s interval. This time interval relates to a vertical resolution of $50 \mathrm{~m}$, assuming a typical balloon-ascending rate of $5 \mathrm{~m} \mathrm{~s}^{-1}$. The controlling unit compares all measurements undertaken within a single 10 -s interval. The spectrum with the highest irradiance values without any saturation, thus having the best signal-to-noise ratio, is selected as being representative for the 10 -s time period. Choosing the meteorological measurements taken with the smallest time delay from the representative optical spectrum synchronizes the optical and meteorological datasets. The synchronized datasets are finally transferred from the controlling unit to the transmitter of the radiosonde.

The controlling unit adapts the integration time of the spectrometer for the case that one or more channels 
show saturation for incoming photons. If saturation is detected in three consecutive measurements, the controlling unit decreases the integration time in preselected steps from $255 \mathrm{~ms}$ down to $20 \mathrm{~ms}$.

Alternatively, the spectrometer can be operated in the calibration mode. Data are then transferred to the ground station via a cable connection with 19200 baud. The higher transmission rate allows the transfer of the data of all 2048 channels for all measured spectra and all meteorological data. In the calibration mode, the adaptive integration time is disabled. Measurements are undertaken with a fixed integration time, selectable prior to the measurement.

\section{Optical characterization}

The spectrometer covers the wavelength range between 200 and $850 \mathrm{~nm}$. The dispersed signal in the spectrometer is detected with a CCD array with 2048 channels. The optical resolution corresponds to $1.34 \mathrm{~nm}$ FWHM (Ocean Optics 2005).

The main purpose of the laboratory experiments was the characterization of the temperature dependence of the spectrometer. During a balloon ascent the spectrometer temperature decreases by about $15 \mathrm{~K}$. Temperature changes affect (i) the dark signal, (ii) the accurate wavelengths of the spectrometer channels, and (iii) the measured signal strength.

The spectrometer signal is recorded with an internal unit corresponding to counts per integration period, which is proportional to the incoming photons in this period.

\section{a. Dark signal}

In the laboratory the dark signal was measured by attaching a black cover on top of the optical entrance of the sonde. A typical dark signal is shown in Fig. 3. In this example, the mean dark signal of all channels corresponds to 105 counts, with a standard deviation of \pm 2 counts. We analyzed the dark signal for 10 spectrometers of the same type at different temperatures. Though measuring different absolute dark signals, all 10 spectrometers showed a similar linear relationship between the mean dark signal and the temperature (Fig. 4).

For example, for spectrometers 1932 and 3658 slopes of -5.53 counts per kelvin $\left(R^{2}=0.994, \mathrm{rmsd}=3.60\right)$ and -5.39 counts per kelvin $\left(R^{2}=0.997\right.$, rmsd $\left.=2.09\right)$ were calculated for the linear regression lines. The slope for spectrometer 3673 was calculated with only two measurements at two different temperatures and corresponds to -5.01 counts per kelvin.

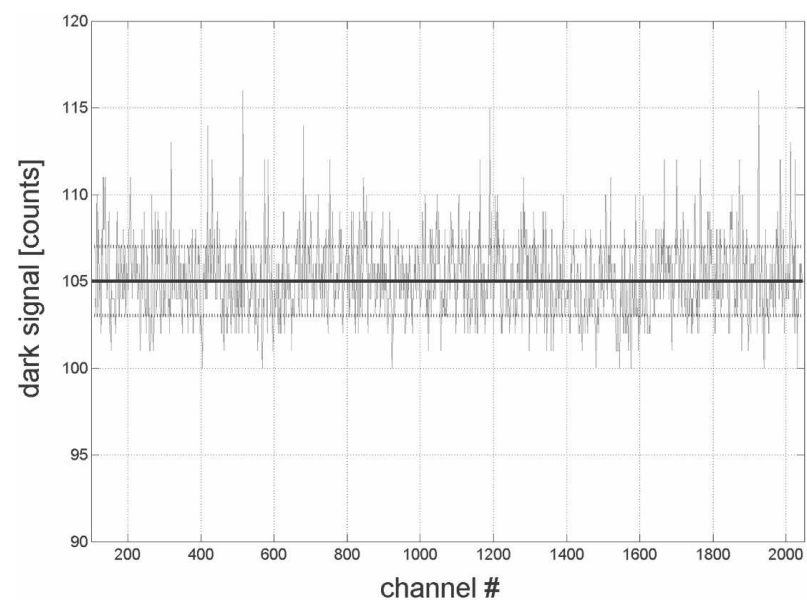

FIG. 3. Dark signal measured with spectrometer 3658 with an integration time of $t_{\text {int }}=250 \mathrm{~ms}$ at $26^{\circ} \mathrm{C}$ in a climate chamber. The solid line marks the mean dark signal of 105 counts, and the dotted lines correspond to the standard deviation of \pm 2 counts.

The temperature-induced dark signal changes can be corrected using the laboratory results. Alternatively, the wide wavelength range of the spectrometer offers the possibility for an in-flight correction. The UV-C wavelengths at the beginning of the detected spectrum $(\leq 250 \mathrm{~nm})$ are in fact dark channels for the miniature spectrometer, since the incoming solar irradiances at these wavelengths are negligible in the stratosphere and below. The penetration depth of solar radiation at a wavelength of $250 \mathrm{~nm}$ is about $40-\mathrm{km}$ altitude (Brasseur and Solomon 1986). At this altitude the radiation is attenuated to $e^{-1}$ of its intensity on top of the atmosphere and below the detection limit of the optical sonde. Therefore, the signal of channel 1 can be regarded as a quasi-dark signal.

To establish how well the mean dark signal is represented by the dark signal of a single channel, the temperature dependence of the mean dark signal was compared with the dark signal detected at channel 1 for spectrometer 3658. Almost identical slopes (-5.392 and -5.390 counts per kelvin) were found for both cases (Fig. 5). Additionally, Fig. 5 shows the differences between the dark signal of channel 1 and the mean dark signal. The differences are less than \pm 1 count, and thus are smaller than the standard deviation ( \pm 2 counts) of the mean dark signal (Fig. 3).

In addition to the laboratory measurements, Fig. 4 shows the detected signal of channel 1 taken during the flight from spectrometer 3673 . The calculated linear regression line for the relationship of the signal to the temperature has a slope of -5.4 counts per kelvin $\left(R^{2}\right.$ $=0.98, \mathrm{rmsd}=3.79)$. The slope and the absolute values of the dark signal are in good agreement with the labo- 


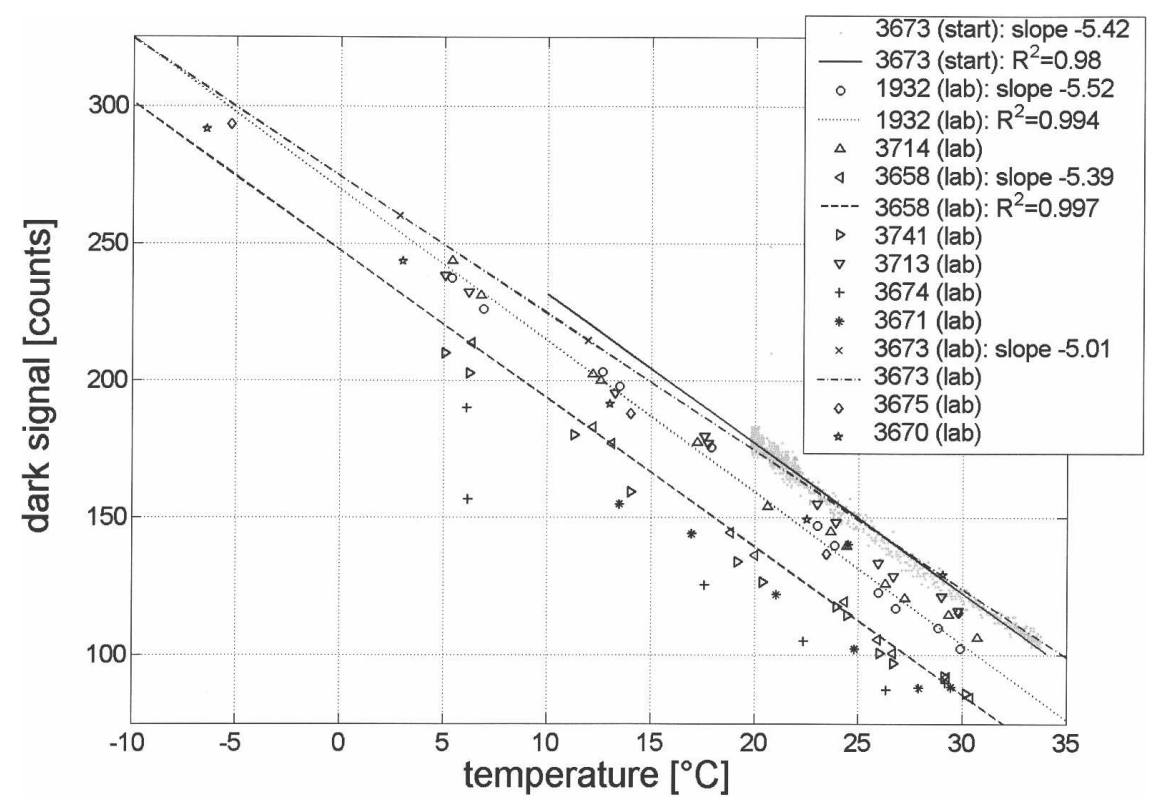

FIG. 4. Dark signal vs temperature measured with an integration time of $t_{\text {int }}=500 \mathrm{~ms}$ for 10 different spectrometers in the laboratory (lab), plotted with different symbols. The regression lines calculated from the laboratory measurements for spectrometers 1932, 3658, and 3673 are also shown. The gray asterisks mark the measured dark signal at channel 1 for spectrometer 3673 during a balloon ascent (start), recorded with an integration time of $t_{\mathrm{int}}=$ $50 \mathrm{~ms}$. The solid line is the calculated regression line for the ascent.

ratory dark signal measurements of this spectrometer, which demonstrates that the changes of the mean dark signal can be corrected reasonably with the data obtained during ascent. We applied this in-flight dark signal correction to the flight data discussed here. In contrast to a correction based on the laboratory results, this
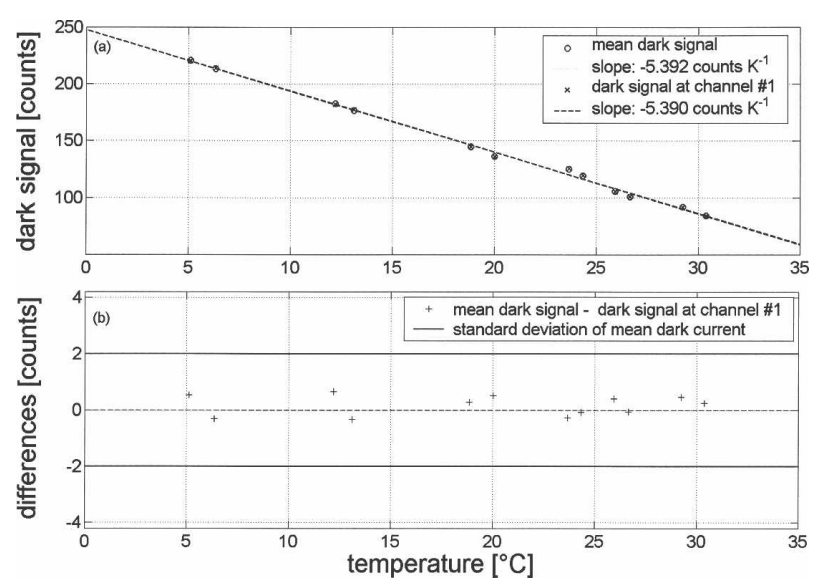

FIG. 5. (a) Measured dark signal of spectrometer 3658 as a function of the temperature $\left(t_{\text {int }}=500 \mathrm{~ms}\right)$. The mean dark signal and the dark signal of channel 1 are shown. (b) Differences between the dark signal of channel 1 and the mean dark signal. The standard deviation of the mean dark signal averaged over all channels is represented by the solid lines. method is independent of any changes of the dark signal behavior over time, which may occur during transport or storage.

\section{b. Spectral calibration}

The relationship of the individual wavelength $(\lambda)$ to channel number can be expressed using a third-order polynomial (Ocean Optics 2003). The determined wavelengths drift slightly as a function of time and environmental conditions (Ocean Optics 2003). In contrast to this slow storage drift, the temperature changes during the flight cause an additional fast wavelength drift. Wavelength calibration measurements under different thermal conditions were carried out for various spectrometers with a pencil-style spectral calibration mercury argon ( $\mathrm{HgAr})$ lamp as the standard radiation source. These tests showed that different spectrometers have slightly different drift behaviors, and those differences exist within the spectrum of each spectrometer. Figure 6 shows examples of the measured wavelength drift of channel 420 of spectrometers 3673 and 3658 measured in the laboratory. The wavelength of the signal detected at a selected channel is decreasing with increasing temperature. Toward higher temperatures the wavelength drift becomes smaller. The typical temperature change of the spectrometer during a flight is 


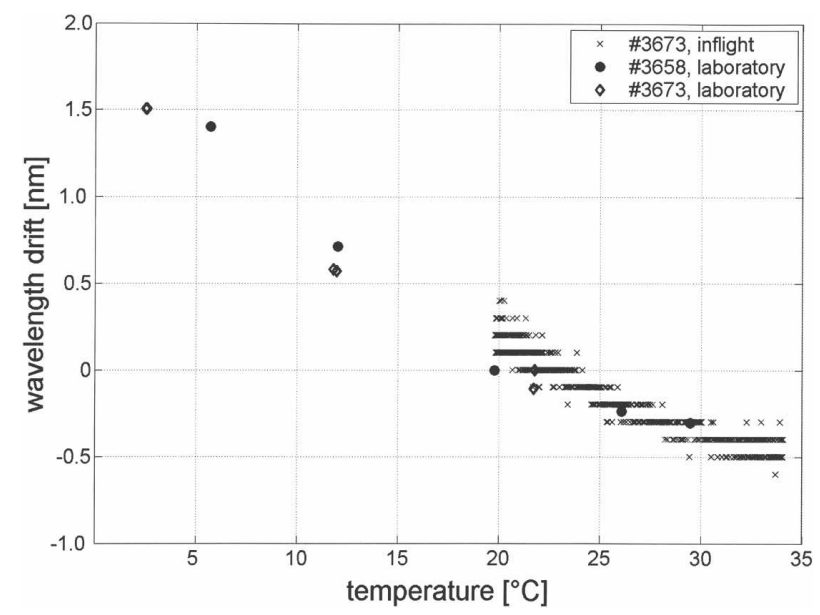

FIG. 6. Wavelength drift of channel 420 measured in the laboratory (spectrometers 3658 and 3673) and during the flight (spectrometer 3673). A wavelength drift of 0 corresponds to the channel-to-wavelength relationship determined by the first calibration of the spectrometer. For the laboratory measurements, the actual channel-to-wavelength relationship and the resulting wavelength drift were determined with a $\mathrm{HgAr}$ light source. For the flight measurements the nominal wavelengths of the measured spectra are changed by a systematic wavelength shift of $0.1 \mathrm{~nm}$ until best agreement of the Fraunhofer structures in the measured and a reference spectrum were obtained.

less than $15 \mathrm{~K}$ due to the insulating effect of the polystyrene housing. The wavelength drift during the flight can be expected to be on the order of $1 \mathrm{~nm}$. The laboratory results would allow us to calculate a temperature-drift function. However, this calculation would not consider the unknown influence of the storage drift.

The analysis of trace gas absorption requires high wavelength accuracy, since the absorption coefficients change drastically with the wavelength. Therefore, a method developed by Huber et al. (1993) was applied to determine and correct in-flight wavelength shifts for each measured spectrum. This method includes a comparison of the Fraunhofer structures of each measured spectrum with the same structures of the extraterrestrial spectrum. To perform the comparison a highly resolved extraterrestrial spectrum (Kurucz 1984, updated by Chance and Spurr 1997) was convolved with the instrument's slit function (Fig. 7). The method does not require the transfer of the extraterrestrial spectrum to the same effective altitude as the measurements. Therefore, no further atmospheric data or radiative transfer model calculations are needed.

As the initial step of the comparison process, the extraterrestrial spectrum is determined for the wavelengths that the manufacturer has given for the spectrometer channels. The measured spectrum is compared with the reference spectrum, and the sum of squares of the residuals is calculated. If the nominal wavelengths of the measured spectrum are changed by a systematic wavelength shift of $\Delta \lambda=0.1 \mathrm{~nm}$ and the convolution of the extraterrestrial spectrum is done for the new wavelength values, the sum of squares of the residuals will also change. As the minimal sum of squares indicates the best agreement of the Fraunhofer structure of the measured and the reference spectrum, the position of the minimum gives the wavelength shift that has to be added to the measured spectrum in order to get an optimum agreement with the reference spectrum. It is possible to determine the wavelength shift within the accuracy of the systematic wavelength shift $\Delta \lambda$ (here $0.1 \mathrm{~nm}$ ), which might be smaller than the spectral resolution of the spectrometer. Figure 7 shows an example. One spectrum measured by spectrometer 3673 is illustrated as a function of the wavelengths given by the manufacturer and of the corrected wavelengths. The observed drift of $1.1 \mathrm{~nm}$ for the wavelength range between 300 and $350 \mathrm{~nm}$ is a combination of the slow storage drift and the fast drift responding to the thermal conditions during the measurement.

The laboratory measurements demonstrate that the wavelength drifts are different for separate parts of the spectrum. Therefore, the comparison of the Fraunhofer structures was performed individually for wavelength intervals of about $50 \mathrm{~nm}$ in the analyzed wavelength range.

The correction method was applied to all spectra recorded during the ascent. Figure 6 shows the drift of

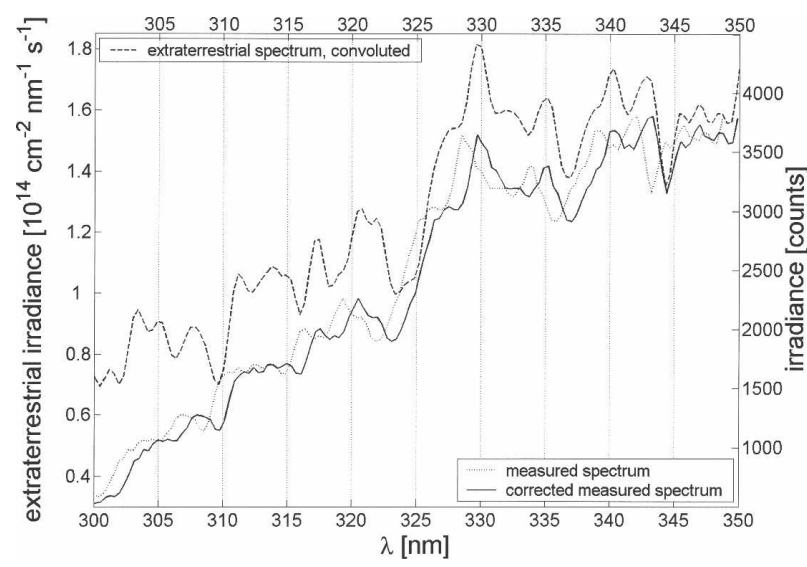

FIG. 7. Example of the correction of a measured spectrum. The uncorrected spectrum was recorded at an altitude of about $32 \mathrm{~km}$, with an integration time of $240 \mathrm{~ms}$. The corrected spectrum exhibits the best agreement of the Fraunhofer structures with the extraterrestrial spectrum. For the comparison the extraterrestrial spectrum was convolved with the instrument's slit function. The absolute intensities of the spectra differ significantly because of instrumental differences. However, these differences do not influence the method of the correction of the spectrum. 

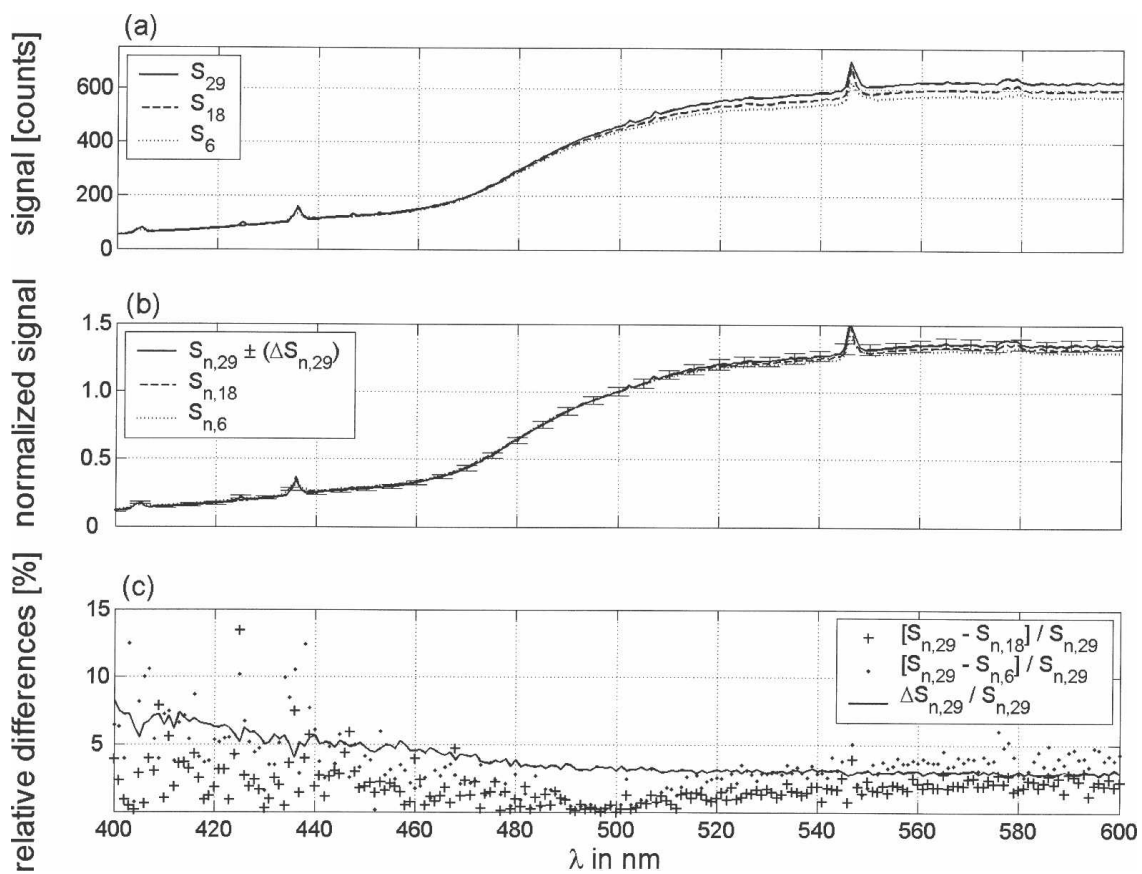

FIG. 8. Temperature dependence of the measured signal. (a) Spectra from a continuous light source detected at three spectrometer temperatures (subscripts indicate the temperature) in the laboratory with an integration time of $t_{\text {int }}=250 \mathrm{~ms}$. (b) Spectra at the three temperatures normalized to the signal at $\lambda=500 \mathrm{~nm}$. Error bars represent the absolute errors of the normalized signal at $29^{\circ} \mathrm{C}$. (c) Relative differences between the normalized signals at $29^{\circ}$ and $18^{\circ} \mathrm{C}$, and $29^{\circ}$ and $6^{\circ} \mathrm{C}$, respectively. The relative error of the normalized signal at $29^{\circ} \mathrm{C}$ is also shown.

channel 420 obtained during the ascent of spectrometer 3673 up to an altitude of $42 \mathrm{~km}$ versus the spectrometer's temperature. The drift is shown relative to the first determined channel-to-wavelength relationship for that measurement, thus depending only on temperature changes. Evidently, this in-flight correction method shows a dependence of the wavelength drift on the spectrometer's temperature comparable to the measured dependencies in the laboratory.

\section{c. Intensity calibration}

The spectrometer's temperature also influences the strength of the detected signal. The effect is different for every spectrometer and shows a smooth variation with the wavelength. Figure 8 shows the signal detected from a constant light source (tungsten-halogen, $150 \mathrm{~W}$ ) measured at three different temperatures $\left(6^{\circ}, 18^{\circ}\right.$, and $29^{\circ} \mathrm{C}$ ). Since only the ratio of two signals at different wavelengths will be used for the analysis, the influence of temperature changes on such a ratio was analyzed. The measured signal in the range from 400 to $600 \mathrm{~nm}$ was normalized to the measured signal at wavelength $\lambda=450,500$, and $550 \mathrm{~nm}$ for the three investigated temperatures. Figure 8 shows the results for $\lambda=500 \mathrm{~nm}$.
The relative differences between the normalized signals are calculated. As expected, the relative differences are smallest for wavelengths close to $500 \mathrm{~nm}$. These relative differences are compared to the relative error of the normalized irradiance measurements at $29^{\circ} \mathrm{C}$. For the large temperature difference of $23 \mathrm{~K}$ $\left(\Delta T=29^{\circ}-6^{\circ} \mathrm{C}\right)$, the differences of the signal ratios for the range of $475-525 \mathrm{~nm}$ are always below the relative error of the signal at $29^{\circ} \mathrm{C}$. For the smaller temperature difference of $11 \mathrm{~K}\left(\Delta T=29^{\circ}-18^{\circ} \mathrm{C}\right)$, the wavelength range for which the differences between the ratios are below the relative error of the signal at $29^{\circ} \mathrm{C}$ extends from 470 to $545 \mathrm{~nm}$. This shows that for the visible part of the spectrum, the temperature-dependent variation of the measured irradiance adds an additional error, which is smaller than the relative error of the signal measurement, as long as the wavelength interval is less than $25 \mathrm{~nm}$.

Because of the lack of a light source with sufficient intensity in the UV, the above measurements could not be performed for wavelengths shorter than $400 \mathrm{~nm}$. As neither major changes within the examined wavelength range, nor any discontinuities at the ends of the wavelength range, were observed, we assumed that the ob- 

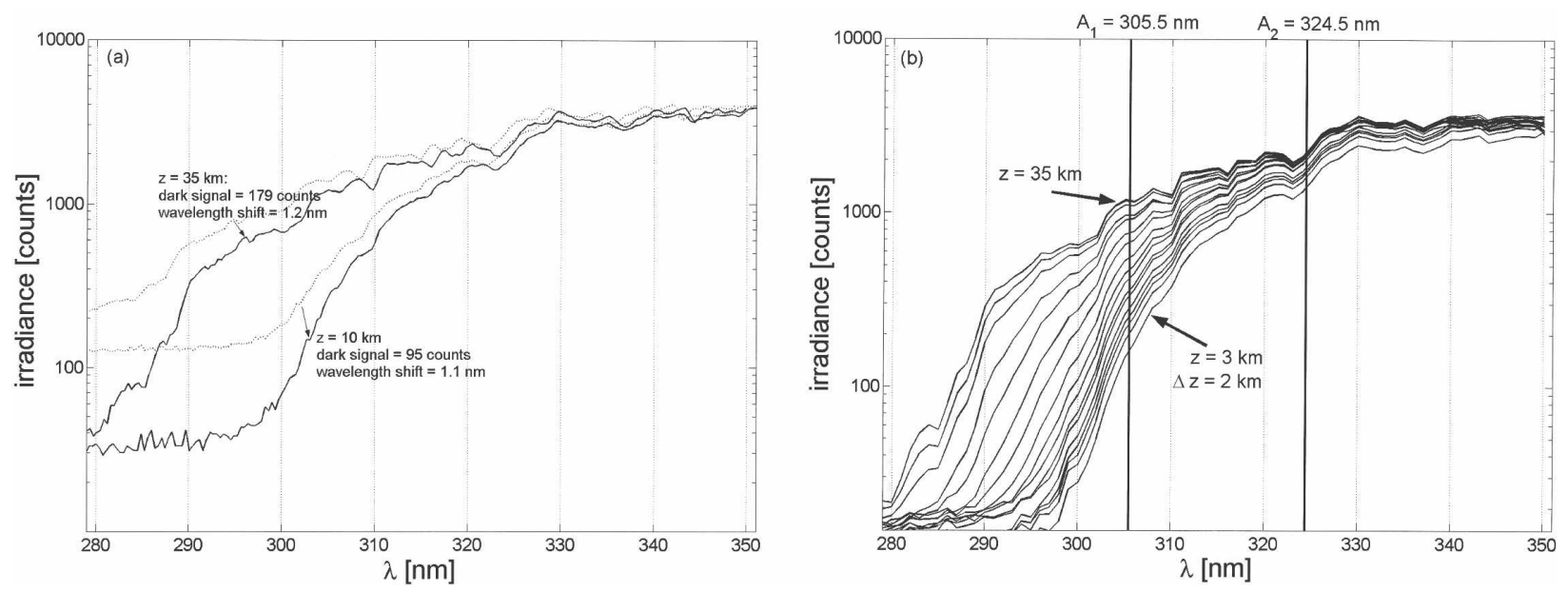

FIG. 9. Measured spectra in the UV range. Flight data are taken from spectrometer 1932, launched on 18 Jul 2005 at the Meteorological Observatory Hohenpeissenberg, Germany. Integration time during the flight was $t_{\text {int }}=240 \mathrm{~ms}$. (a) Spectra, measured at $10-$ and 35-km altitude as detected (dotted line) and with applied dark signal and wavelength shift correction (solid line). (b) Corrected spectra at altitudes between 3 and $35 \mathrm{~km}$. The spectral data are averaged for altitude intervals of $2 \mathrm{~km}$.

served temperature effect on the signal ratios of two wavelengths is comparable in the UV range of the spectrometer. The wavelength pairs used for the trace gas analysis (see below) typically differ by $20 \mathrm{~nm}$, which is within the described tolerance.

\section{Flight data}

In 2004 and 2005, nine balloon flights were performed with the new system, and the retrieved ozone profiles were compared with other measurements. Here, we show results from one flight to illustrate the sensor performance. The sonde was launched on 18 July 2005 at the Meteorological Observatory Hohenpeissenberg $\left(48^{\circ} \mathrm{N}, 11^{\circ} \mathrm{E}\right)$ of the German Weather Service.

\section{a. Irradiance measurements}

The sensor detected the solar irradiance during the ascent. The described in-flight corrections were applied on the transmitted spectral data: subtraction of the dark signal and wavelength correction (Fig. 9a). The resulting UV solar spectra are averaged over $2-\mathrm{km}$ intervals and shown at altitudes between 3 and $35 \mathrm{~km}$ in Fig. 9b.

Almost no radiation with wavelengths shorter than $300 \mathrm{~nm}$ reaches the surface, because of the strong ozone absorption in the Hartley band $(200-310 \mathrm{~nm})$. The cutoff wavelength of the miniature spectrometer at 2-km altitude is $297 \mathrm{~nm}$. Only radiation with longer wavelengths is detectable at this altitude.
The measured intensity of the short wavelengths $(<320 \mathrm{~nm})$ increases rapidly toward higher altitudes. Accordingly, the spectrometer's cutoff wavelength shifts toward shorter wavelengths. Compared to these changes, which encompass several orders of magnitude, the intensity changes due to the decreasing attenuation effect of scattering from air molecules and aerosols toward higher altitudes are rather small. Therefore, the measured intensity at the longer wavelengths, where the ozone absorption is smaller $(>320 \mathrm{~nm})$, remains relatively unchanged with altitude.

\section{b. Ozone vertical columns}

PIOS measures the global irradiance because its detector has an FOV of $180^{\circ}$. With the radiative transfer model LibRadtran (Mayer and Kylling 2005), the fraction of direct and diffuse irradiance was computed for the wavelength range from 300 to $340 \mathrm{~nm}$ and a solar zenith angle of $30^{\circ}$. At $10-\mathrm{km}$ altitude, the direct irradiance amounts to $85 \%$ of the global irradiance. At $20 \mathrm{~km}$, the direct irradiance amounts to $95 \%$ and diffuse irradiance amounts to $5 \%$ of the global irradiance. Toward higher altitudes, the fraction of direct light increases. For the following analysis the indirect component was neglected. The vertical ozone column $\mathrm{VC}_{\mathrm{O}_{3}}$ above the sonde in each altitude $z$ can be computed from the measurements using two wavelength pairs (here $A$ and $D$ ), according to the Dobson spectrophotometer algorithm (Komhyr 1980): 


$$
\begin{aligned}
\mathrm{VC}_{\mathrm{O}_{3}}= & \frac{\ln \frac{I_{A_{1}, 0}}{I_{A_{2}, 0}}-\ln \frac{I_{D_{1}, 0}}{I_{D_{2}, 0}}-\left(\ln \frac{I_{A_{1}}}{I_{A_{2}}}-\ln \frac{I_{D_{1}}}{I_{D_{2}}}\right)}{\left(\Delta \sigma_{\mathrm{O}_{3}, A}-\Delta \sigma_{\mathrm{O}_{3}, D}\right) \mathrm{AMF}} \\
& -\frac{\left(\Delta \tau_{\mathrm{Ray}, A}-\Delta \tau_{\mathrm{Ray}, D}\right) \frac{p(z)}{p_{0}}}{\left(\Delta \sigma_{\mathrm{O}_{3}, A}-\Delta \sigma_{\mathrm{O}_{3}, D}\right)}
\end{aligned}
$$

where $I_{\lambda}$ is the measured radiation at the wavelength $\lambda$ (here $\lambda=A_{1}, A_{2}, D_{1}$, and $D_{2}$ ). The extraterrestrial radiation has the additional subscript 0 , for example, $I_{A_{1}, 0}$. The expressions $\Delta \sigma_{\mathrm{O}_{3}}$ and $\Delta \tau_{\text {Ray }}$ represent the differences between the absorption cross sections of ozone $\left(\sigma_{\mathrm{O}_{3}}\right)$ and the Rayleigh scattering cross sections $\left(\tau_{\text {Ray }}\right)$ at the wavelengths of the corresponding pair (e.g. $\Delta \sigma_{\mathrm{O}_{3}, A}=\sigma_{\mathrm{O}_{3}, A_{1}}-\sigma_{\mathrm{O}_{3}, A_{2}}$ ) (Table 1). The airmass factor (AMF) is the ratio of the actual and vertical paths of solar radiation through the atmosphere. The observed pressure at altitude $z$ and at mean sea level are expressed by $p(z)$ and $p_{0}$, respectively.

The extraterrestrial radiation is estimated using the measurements at the burst point $(35.8 \mathrm{~km})$ of the balloon, assuming an amount of ozone of $0.5 \times 10^{18} \mathrm{~mol}-$ ecules per square centimeter in the vertical column above the sonde. The ozone absorption cross sections are taken from Malicet et al. (1995). The Rayleigh scattering cross sections are calculated according to $\mathrm{Bu}-$ choltz (1995). The airmass factor is calculated using the approximation formula of Kasten and Young (1989), which considers the solar elevation and the curvature of the atmosphere.

The calculated vertical ozone columns from altitude $z$ to the top of the atmosphere (referred to as vertical ozone column profiles) are plotted versus altitude for both the $A D$ and the $B D$ wavelength combinations (Fig. 10).

\section{c. Estimation of the vertical resolution of the ozone profiles}

The retrieved vertical ozone column profiles (Fig. 10) show significant noise, composed of the noise of the instrument and of the performed numerical operations. Running means are calculated for the vertical ozone column profiles by averaging 50 data points. The running mean profile calculated for the $A D$ data is included in Fig. 10. The error bars in Fig. 10 illustrate the standard deviation of the vertical ozone column profile.

Comparing the noise with the slope of the averaged vertical ozone column profile gives the minimum altitude difference, for which a significant change in the vertical ozone column density can be calculated. The comparison yields the possible vertical resolution of the

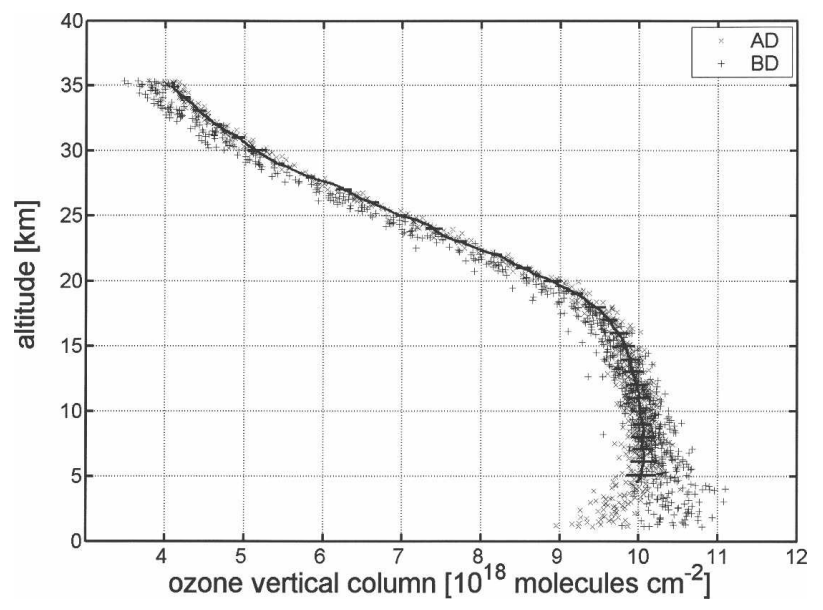

FIG. 10. The gray crosses are the vertical column density of ozone on 18 Jul 2005, calculated with the adopted Dobson algorithm for the combination of the $A$ and $D$ wavelength pair (+) and the $B$ and $D$ wavelength pair (x). The solid line is a running mean of the vertical ozone column profile (only $A D$ ) calculated by averaging 50 data points. The error bars illustrate the standard deviation of the vertical ozone column profile.

ozone concentration profile. In other words, the possible determination of the ozone concentration between two different altitudes depends on the detectable differences in the vertical ozone columns at these altitudes. Higher vertical resolution $(<1000 \mathrm{~m})$ is achieved for altitudes above $18 \mathrm{~km}$. For altitudes below $18 \mathrm{~km}$ the vertical resolution is lower $(>1000 \mathrm{~m})$. Large changes in the vertical ozone columns at different altitudes (corresponding to a large vertical ozone gradient) result in a high vertical resolution. Further, a large signal-to-noise ratio decreases the minimum detectable differences, thus resulting in a high vertical resolution. Large signal-to-noise ratios are obtained with large solar radiation intensities (e.g., high sun elevation) and/or with longer integration times of the spectrometer.

\section{d. Ozone profiles}

The ozone concentration profile is derived by differentiating the vertical ozone column profile. Considering the limitations of the possible vertical resolution, the vertical ozone columns are averaged with a running mean using the mean vertical resolution for the launch as averaging length (approximately $1 \mathrm{~km}$ ). The smoothed vertical ozone column profile is divided into 1-km sections, each consisting of approximately 30 data points. For each section, a straight line was fitted to the data using linear regression. The slope of each line gives the ozone number density for the corresponding altitude interval. The standard deviation of the regression line allows us to calculate the uncertainty of the 

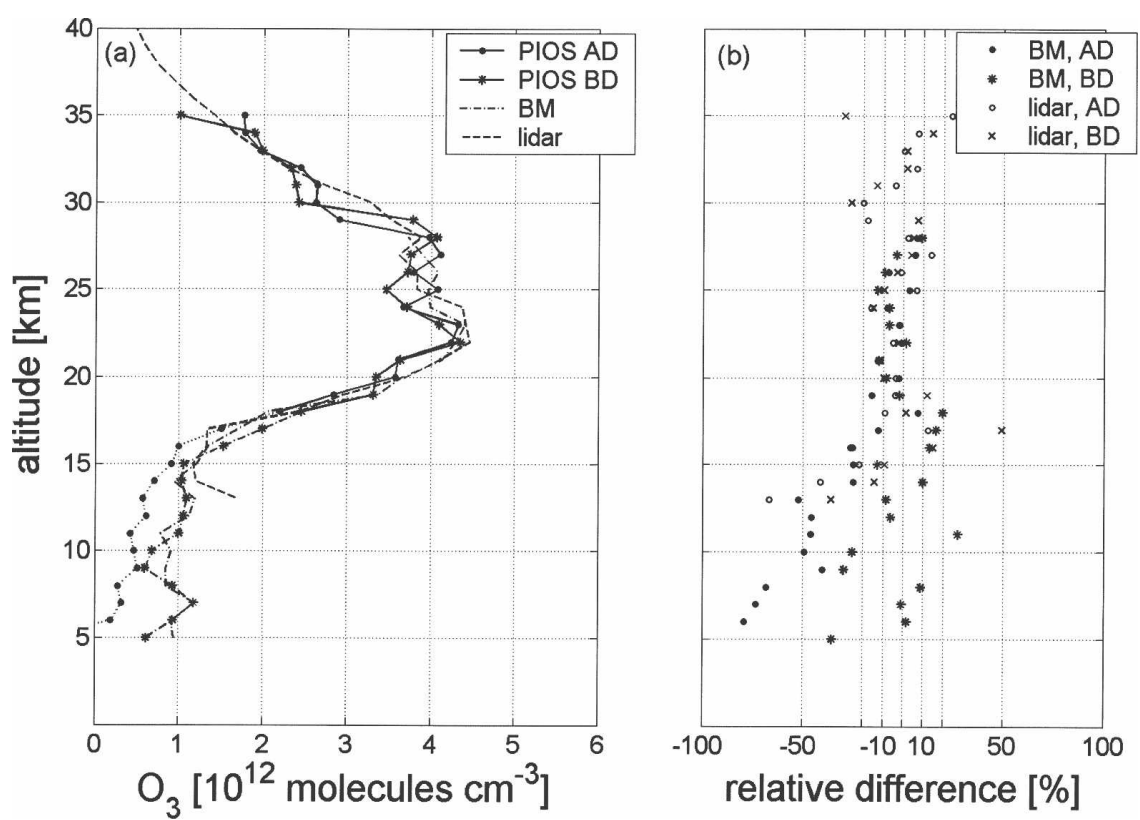

FIG. 11. (a) Calculated ozone profiles for the flight carried out on $18 \mathrm{Jul} 2005$. The profiles are plotted with solid lines for a high vertical resolution $(<1000 \mathrm{~m})$ and with dotted lines for a low vertical resolution $(>1000 \mathrm{~m})$. Also shown are the profiles obtained with the BrewerMast sonde and with the lidar system. (b) Relative differences between the profiles of the Brewer-Mast sonde and PIOS, and between the profiles of the lidar measurement and PIOS. In each case differences are calculated separately for the PIOS $A D$ and $B D$ profiles.

determined slope, thus giving an estimation of the retrieval error of the ozone concentration. In the upper troposphere and lower stratosphere, where the vertical resolution is lower than the used average length (mean vertical resolution), the uncertainty of the ozone concentration values can be estimated between $30 \%$ and $70 \%$. Between $15-$ and $30-\mathrm{km}$ altitude, where the vertical resolution is higher than the mean vertical resolution and the largest changes in the vertical ozone columns are detected, the estimated uncertainty varies between $10 \%$ and $15 \%$. Above $30 \mathrm{~km}$ the uncertainty of the ozone concentration values varies between $15 \%$ and $20 \%$.

Figure 11 shows a comparison of ozone profiles measured by the new optical sonde, an electrochemical ozone sonde (BM), and an ozone lidar. The relative precision of the BM sonde lies between $11 \%$ and $13 \%$ in the troposphere and increases to $4 \%$ at $20-\mathrm{km}$ altitude. At $30-\mathrm{km}$ altitude, it is approximately $15 \%$ (Smit and Kley 1998).

Typical values for the relative errors of the ozone profile detected with the ozone lidar are $13 \%$ at $15-\mathrm{km}$ altitude, $3 \%-5 \%$ between $20-$ and $40-\mathrm{km}$ altitude, and $15 \%$ at $45-\mathrm{km}$ altitude (Steinbrecht et al. 1997). The two sondes were launched at 0915 UTC with a time difference of about $3 \mathrm{~min}$ at the Meteorological Obser- vatory Hohenpeissenberg. Ozone profile measurements with the ground-based ozone lidar at Hohenpeissenberg were performed the following night.

For altitudes above $18 \mathrm{~km}$, the relative differences between the PIOS measurements and the two comparison measurements are mainly within $20 \%$. Below 18 $\mathrm{km}$ altitude the discrepancies are larger. The profile obtained with the wavelength combination $B D$ matches the profile of the Brewer-Mast sonde better: relative differences range between $10 \%$ and $30 \%$. The profile calculated with the wavelength combination $A D$ shows differences exceeding $50 \%$. This reflects the fact that the relative contribution of the ozone-absorbing wavelength is changing to longer wavelengths at lower altitudes (Brasseur and Solomon 1986). Subsequently, the irradiance at shorter wavelengths is decreasing toward lower altitudes. The detected irradiance at the shorter wavelengths of pair $A$ is smaller than the detected values at the longer wavelengths of pair $B$, thus resulting in a smaller signal-to-noise ratio and a larger uncertainty for the measurements at the shorter wavelength pair $A$.

\section{Discussion and suggested refinements}

This paper reports the successful realization of a working prototype of a small-size balloon-borne optical 
sonde for measuring atmospheric trace gases, demonstrating its overall functionality. We used easily available hardware and techniques for the sonde and applied a fairly simple method to calculate the first ozone profiles. This instrument was relatively inexpensive to construct and deploy and yet was able to measure reliable ozone profiles in the stratosphere. That said, the present prototype has limitations, due, in part, to unoptimized hardware and simplifications utilized during the analysis process. For example, the quantification of atmospheric $\mathrm{NO}_{2}$ or any other trace gas is not yet possible, partly because of an insufficient spectral resolution. Recognizing these limitations and implementing improvements will enable the next generation to make the step from a working prototype to a reliable scientific instrument. Here we list the limitations of our instrumentation and possible error sources in our retrieval calculations, discuss their effects, and suggest possible improvements.

One weakness of the current instrument is the small signal-to-noise ratio, especially in the UV wavelength range of interest. Increasing the signal-to-noise ratio of the irradiance measurements would increase their precision, resulting in an improved accuracy of the retrieved ozone profiles. This could be achieved by selecting an integration time optimized for the wavelength range of interest. The prototype spectrometer does not use all of the light entering the instrument, since the height of the CCD array does not coincide with the slit height. The implementation of an additional collecting lens in the optical path of the spectrometer (available from the manufacturer) would focus the slit image onto the CCD detector array, which would also improve the signal-to-noise ratio.

The miniature spectrometer can be equipped with other gratings. We recommend selection of a grating with a smaller wavelength coverage, thus offering a higher spectral resolution, which is necessary for the analysis of weaker absorbers such as $\mathrm{NO}_{2}$ or $\mathrm{BrO}$.

We neglected the influence of temperature changes on the signal strength in the UV range, based on the quantification of temperature effects on the VIS range of the spectrum. This assumption might not be entirely true, as the order sorting filters or the UV-enhancing composite phosphor coating on the CCD may cause different characteristics at different wavelength ranges. To confirm that this assumption is valid or, if not, to correct for possible temperature effects requires measurements with a light source providing enough energy in the UV.

The unpredictable oscillations of the payload prevented us from applying a cosine correction to the signal because the necessary incident angle information of the measured spectral data was unobtainable. As described in section 3, we selected the spectra with the largest signal-to-noise ratio as being representative of each 10-s interval. The largest signal is achieved when the incoming radiation penetrates the diffuser surface along its normal. Therefore, the incident angles of the representative spectra are closest to the normal of the diffuser surface. By analyzing the irradiance signal ratios we have the advantage that most of the incidentangle-related errors would cancel out. Measuring the cosine response of the individual diffuser, however, would allow an estimation of the resulting measurement error. Furthermore, the optimal diffuser for this purpose could be identified by testing diffusing material of different qualities. Incorporating the optimal diffuser would improve the quality of the irradiance measurements.

As we did not experience any major problems obviously caused by stray light, we did not perform explicitly stray light measurements. Longwave stray light may increase the detected signals at shorter-wavelength channels. That bias would certainly affect the accuracy of the retrieved ozone profile. Quantifying a possible stray light effect would allow adequate precautions to be taken, for example, by applying optical filters that block the interfering wavelengths.

Instrument temperature changes during flight might cause a non-negligible change of the entrance slit width, resulting in different slit functions at different temperatures. As we used only one slit function when determining the temperature-induced wavelength shift, it is possible that this procedure introduced an additional error. Determining the spectrometer's slit function at different temperatures will be necessary to improve the spectral accuracy of the spectral measurements.

We have assumed for our analysis that the instrument is only measuring the direct solar irradiance, which is certainly not true. Especially in the lower stratosphere and troposphere the fraction of indirect irradiance increases. Neglecting this phenomenon explains part of the increased error of the retrieved ozone profile toward lower altitudes. A radiative transfer model (RTM) would allow for a more realistic analysis of the measured spectra.

The ozone profile presented in this work was determined by the analysis of four separate wavelengths and does not take advantage of the abundance of spectral information offered by the new sonde. We expect that the analysis of all the spectral information will lead to a higher accuracy of the ozone profiles for an extended altitude region. The spectra may also be used for the analysis of other trace gases absorbing in the observed wavelength range (e.g., $\mathrm{NO}_{2}$ or $\mathrm{BrO}$ ). For example, the 
differential optical absorption spectroscopy technique (Platt 1994) could be adapted for use with the new instrument to derive simultaneously the column amounts of different absorbers.

Finally, the analysis of the measured solar spectra could be coupled to a full RTM. Besides an improved estimation for the airmass factor and scattering terms, this would allow for an inversion algorithm to retrieve the trace gas concentration profiles and would introduce the possibility of considering the uncertainties of the experimental setup, etc., for a very quantitative and detailed error analysis.

\section{Conclusions}

The balloon version of PIOS consists of a complete sounding system containing a portable ground station and a small, lightweight $(1.7 \mathrm{~kg})$ balloon-borne optical sonde. The autonomous system makes launches independent of special launching sites possible, similar to those for standard radiosondes.

The optical characteristics of the spectrometer depend on the spectrometer's temperature. During a balloon ascent through the atmosphere the sensor experiences rather large temperature changes $(\Delta T \approx 15 \mathrm{~K})$. The temperature-induced wavelength shift, the signal changes, and the dark signal behavior were quantified in laboratory experiments. We derived correction methods to compensate for the influence of the temperature changes during the flight. This allows for reliable irradiance measurements without an active temperature controlling system.

Data from one of the test flights are used to retrieve ozone profiles. These were compared with the ozone profiles of two independent comparison measurements (lidar and Brewer-Mast sonde). The assumptions made in the retrieval algorithm are not valid at lower altitudes, which is reflected in the increasing discrepancies between the PIOS and the comparison ozone profiles toward lower altitudes. Above $18 \mathrm{~km}$, where a high vertical resolution of the PIOS ozone profiles is achieved $(<1000 \mathrm{~m})$ and the estimated retrieval error varies between $10 \%$ and $15 \%$, the ozone profiles agree reasonably well with the comparison profiles.

Acknowledgments. The comparison data were provided by the German Weather Service, Hohenpeissenberg Observatory: we thank Hans Claude and his team for the ozone data from the Brewer-Mast sonde, and Wolfgang Steinbrecht and Fritz Schönenborn for providing the lidar data. We are grateful to the ozone group of the Hohenpeissenberg Observatory for their support during our campaign. We also thank Hartwig
Gernandt and Okano Shoichi for the initialization of the project.

\section{REFERENCES}

Brasseur, G., and S. Solomon, 1986: Aeronomy of the Middle Atmosphere: Chemistry and Physics of the Stratosphere and Mesosphere. Kluwer Academic, 452 pp.

Bucholtz, A., 1995: Rayleigh-scattering calculations for the terrestrial atmosphere. Appl. Opt., 34, 2765-2773.

Chance, K. V., and R. J. D. Spurr, 1997: Ring effect studies: Rayleigh scattering, including molecular parameters for rotational Raman scattering, and the Fraunhofer spectrum. Appl. Opt., 36, 5224-5230.

Dobson, G., 1957: Observers handbook for the ozone spectrophotometer. Ann. Int. Geophys. Year, 5, 46-89.

Huber, M., M. Blumthaler, and W. Ambach, 1993: A method for determining the wavelength shift for measurements of solar UV radiation. SPIE Atmos. Radiation, 2049, 354-357.

Kasten, F., and A. T. Young, 1989: Revised optical air mass tables and approximation formula. Appl. Opt., 28, 4735-4738.

Komhyr, W. D., 1980: Operations handbook-Ozone observations with a Dobson spectrophotometer. WMO Global Ozone Research and Monitoring Project Rep. 6, 125 pp.

- R. A. Barnes, G. B. Brothers, J. A. Lathrop, and D. P. Opperman, 1995: Electrochemical concentration cell ozonesonde performance evaluation during STOIC 1989. J. Geophys. Res., 100, 9231-9244.

Kurucz, R., 1984: Solar Flux Atlas from 296 to 1300 nm, Sunspot, New Mexico. National Solar Observatory Atlas 1, Harvard University, $240 \mathrm{pp}$.

Logan, J., and Coauthors, 1999: Trends in the vertical distribution of ozone: A comparison of two analyses of ozonesonde data. J. Geophys. Res., 104, 26 373-26 399.

Malicet, J., D. Daumont, J. Charbonnier, C. Parisse, A. Chakir, and I. Brion, 1995: Ozone UV spectroscopy. II: Absorption cross-sections and temperature dependence. J. Atmos. Chem., 21, 263-273.

Mayer, B., and A. Kylling, 2005: Technical note: The libRadtran software package for radiative transfer calculationsDescription and example for use. Atmos. Chem. Phys., 5, 1855-1877.

Ocean Optics, 2003: USB2000 fiber optic spectrometer installation and operation manual. [Available online at http:// www.oceanoptics.com/technical/usb2000_operating_ instructions.pdf.]

_ 2005: Optical resolution. [Available online at http://www. oceanoptics.com/technical/opticalresolution.asp.]

, 2006: Cosine-corrected irradiance probes. [Available online at http://www.oceanoptics.com/products/irradianceprobes. asp.]

Platt, U., 1994: Differential Optical Absorption Spectroscopy (DOAS). Air Monitoring by Spectroscopic Techniques, M. Sigrist, Ed., Chemical Analysis Series, Vol. 127, WileyInterscience, 27-84.

Richner, H., and S. von Hünerbein, 1999: Grundlagen aerologischer Messungen speziell mittels der Schweizer Sonde SRS 400 (Fundamentals of atmospheric measurements particularly with the Swiss sonde SRS400). SMA-Meteo Schweiz 61, $140 \mathrm{pp}$.

Singh, O. N., and P. Fabian, 2003: Atmospheric Ozone: A Millennium Issue. Special Publication Series, Vol. 1, European Geosciences Union, 147 pp. 
Smit, H., and D. Kley, 1998: Jülich Ozone Sonde Intercomparison Experiment (JOSIE). WMO/GAC Rep., Global Atmosphere Watch Report Series 130, World Meteorological Organization, $108 \mathrm{pp}$.

Solomon, S., R. W. Portmann, T. Sasaki, D. J. Hofmann, and D. W. J. Thompson, 2005: Four decades of ozonesonde measurements over Antarctica. J. Geophys. Res., 110, D21311, doi:10.1029/2005JD005917.

SPARC, 1998: Assessment of trends in the vertical distribution of ozone. SPARC Rep. 1, 289 pp.

Steinbrecht, W., P. Winkler, and H. Claude, 1997: Ozone and temperature measurements with a lidar at Hohenpeissenberg (in German). German Weather Service Rep. 200, 89 pp.

Strong, K., and Coauthors, 2005: MANTRA-A balloon mis- sion to study the odd-nitrogen budget of the stratosphere. Atmos.-Ocean, 43 (4), 283-299.

WMO, 2003: Scientific assessment of ozone depletion 2002. Global Ozone Research and Monitoring Project Rep. 44, World Meteorological Organization, $498 \mathrm{pp}$.

Wolff, M., 2005: Development of a novel balloon-borne optical sonde for the measurement of ozone and other stratospheric trace gases. Ph.D. dissertation, University of Bremen, $150 \mathrm{pp}$. , and W. Ruhe, 2004: Unmanned device for atmospheric measurements (in German). Utility Model DE 202004005530 U1, German Patent and Trademark Office.

Wursteisen, P., 2003: The validation of the ENVISAT chemistry instruments by use of stratospheric balloons and aircraft. 16th ESA Symposium on European Rocken and Balloon Programmes, Vol. SP-530, B. Warmbein, Ed., ESA, 407-413. 